\title{
Neuroprotective effects of testosterone on the morphology and function of somatic motoneurons following the death of neighboring motoneurons
}

\author{
Christine M. Little, Kellie D. Coons, and Dale R. Sengelaub ${ }^{\star}$ \\ Program in Neuroscience and Department of Psychological and Brain Sciences, Indiana \\ University, Bloomington, Indiana 47405
}

\begin{abstract}
Motoneuron loss is a significant medical problem, capable of causing severe movement disorders or even death. We have previously shown that partial depletion of motoneurons from sexually dimorphic, highly androgen-sensitive spinal motor populations induces dendritic atrophy in remaining motoneurons, and this atrophy is attenuated by treatment with testosterone. To test whether testosterone has similar effects in more typical motoneurons, we examined potential neuroprotective effects in motoneurons innervating muscles of the quadriceps. Motoneurons innervating the vastus medialis muscle were selectively killed by intramuscular injection of cholera toxin-conjugated saporin. Simultaneously, some saporin-injected rats were given implants containing testosterone or left untreated. Four weeks later, motoneurons innervating the ipsilateral vastus lateralis muscle were labeled with cholera toxin-conjugated HRP, and dendritic arbors were reconstructed in 3 dimensions. Compared to intact normal males, partial motoneuron depletion resulted in decreased dendritic length in remaining quadriceps motoneurons, and this atrophy was attenuated by testosterone treatment. To examine the functional consequences of the induced dendritic atrophy, and its attenuation with testosterone treatment, the activation of remaining quadriceps motoneurons was assessed using peripheral nerve recording. Partial motoneuron depletion resulted in decreased amplitudes of motor nerve activity, and these changes were attenuated by treatment with testosterone, providing a functional correlate to the neuroprotective effects of testosterone treatment on quadriceps motoneuron morphology. Together, these findings suggest that testosterone has neuroprotective effects on morphology and function in both highly androgen-sensitive as well as more typical motoneuron populations, further supporting a role for testosterone as a neurotherapeutic agent in the injured nervous system.
\end{abstract}

\section{Keywords}

steroids; neuroprotection; morphology; dendrites

\section{INTRODUCTION}

Neurodegenerative disease or nerve injury often results in the loss of spinal motoneurons. For example, amyotrophic lateral sclerosis (ALS), the most common motoneuron disease in adult humans, is characterized by the selective killing of upper or lower motoneurons (as well as small interneurons) in the brain and spinal cord. This cellular degeneration results in

\footnotetext{
"Correspondence to: Dale R. Sengelaub, PhD, Psychology Building, Indiana University, 1101 East 10th Street, Bloomington, Indiana 47405, Phone: (812) 855-9149, Fax: (812) 855-4691, Email: sengelau@ indiana.edu.

Associate Editor: Jeffrey H. Kordower
} 
a progressive muscle weakness, atrophy and spasticity, and ultimately a nearly complete paralysis (Cleveland and Rothstein, 2001). While ALS is the most prevalent, other diseases including the motor neuron diseases and spinal muscular atrophies (e.g., spinal and bulbar muscular atrophy; Kennedy et al., 1968) are also characterized by progressive loss of motoneurons. Similarly, damage to spinal nerves resulting in laceration and avulsion of spinal roots (e.g., cauda equina injury with high impact motor vehicle accidents, Moschilla et al., 2001) can lead to the death of motoneurons and preganglionic autonomic neurons in the spinal cord, resulting in autonomic and motor dysfunction (Hoang et al., 2003).

However, the death of motoneurons is not the only outcome, and importantly, remaining motoneurons after such insults show a variety of morphological and functional changes. For example, injured motoneurons undergo dendritic retraction and atrophy (e.g., Standler and Bernstein, 1984). Similarly, after peripheral axotomy motoneurons show functional and biochemical changes (e.g., Titmus and Faber, 1990; Bisby and Tetzlaff, 1992) as well as dendritic atrophy (e.g., Sumner and Watson, 1971; Brännström et al., 1992; O'Hanlon and Lowrie, 1995).

We have begun to examine the effects of motoneuron loss on the structure and function of surviving motoneurons using a rat model of motoneuron death. Our previous studies have demonstrated that surviving motoneurons respond to the loss of their neighbors with marked somal and dendritic atrophy. Partial depletion of motoneurons from the spinal nucleus of the bulbocavernosus (SNB) results in substantial somal and dendritic atrophy in surviving motoneurons (Fargo and Sengelaub, 2004a,b, 2007). This secondary atrophy is responsible for at least some of the movement deficits that accompany degenerative movement disorders and spinal cord trauma. Indeed, work from our laboratory indicates that this atrophy reduces the excitability of the remaining motoneurons (Fargo and Sengelaub, 2005). Given that we currently lack the technology to replace dead motoneurons, developing the ability to protect surviving motoneurons from secondary atrophy is an important goal.

Gonadal steroids exhibit a wide array of neuroprotective and neurotherapeutic effects (Henderson and Reynolds, 2002; Jones, 1993; Jones et al., 2001; Woolley and Cohen, 2002). For example, testosterone treatment accelerates both axon regeneration and functional recovery following axotomy of spinal or cranial motoneurons (Jones et al., 2001). After crush axotomy of hamster facial motoneurons, treatment with exogenous testosterone accelerates the rate of axon regeneration (Kujawa et al., 1991) as well as the recovery of motor function (Kujawa and Jones, 1990; Kujawa et al., 1989). Using our model of motoneuron loss, we have begun to examine the neuroprotective effects of gonadal steroids on the secondary atrophy induced in nearby surviving motoneurons. Our previous experiments have demonstrated that testosterone is indeed neuroprotective following motoneuron loss. Treatment with exogenous testosterone attenuates the somal and dendritic atrophy, as well as the attenuated excitability, of SNB motoneurons induced by motoneuron loss (Fargo and Sengelaub, 2004a,b, 2005, 2007).

Importantly, as described above, our previous work utilized motoneurons of the SNB, motoneurons which are both sexually dimorphic and highly androgen sensitive. Because of this sensitivity, it is possible that the androgenic effects we observed in SNB motoneurons after induced motoneuron depletion may be unique to this highly androgen-sensitive system. Thus, in this experiment we tested whether other, more typical somatic motoneurons show similar effects of androgen treatment in attenuating dendritic atrophy and concomitant deficits in function after induced motoneuron depletion. 


\section{METHODS}

In rats, each quadriceps muscle of the thigh is comprised of the vastus lateralis, the vastus medialis, the vastus intermedialis, and the rectus femoris (Hebel and Stromberg, 1986). These muscles are innervated by motoneurons located in column 3 of the lateral motor column in the L2 spinal segment (Nicolopoulos-Stournaras and Iles, 1983; Brushart and Seiler, 1987; Al-Majed et al., 2000) and projecting via the femoral nerve to the four muscles of the quadriceps. The distributions of the somata and dendritic arbors of the motoneurons innervating the individual muscles of the ipsilateral quadriceps overlap extensively in the lateral motor column (Nicolopoulos-Stournaras and Iles, 1983; Sengelaub et al., 2006), making it possible to partially and selectively deplete this motor population and study the effects of that depletion, and its potential androgen-sensitivity, on the surviving motoneurons.

\section{Animals}

Adult male Sprague Dawley rats (approximately 100 days old; Harlan) were maintained on a 12:12 hour light/dark cycle, with unlimited access to food and water. We used the toxin saporin, conjugated to the cholera toxin B subunit, to selectively kill motoneurons. Saporin is a ribosome inactivating protein; it kills cells by irreversibly inactivating ribosomes and thereby halting protein synthesis (Stirpe et al., 1992; Stirpe et al., 1983). Cholera toxinconjugated saporin is retrogradely transported from the site of injection, and kills motoneurons innervating the injected musculature within 3-6 days (Fargo and Sengelaub, 2004a).

Rats were anesthetized with isoflurane, and motoneurons innervating the left vastus medialis muscle were selectively killed by intramuscular injection of cholera toxin-conjugated saporin ( $2 \mu 1,0.1 \%$; Advanced Targeting Systems, Inc.). Some of the rats were not treated further (morphology studies, $n=6$; electrophysiology studies, $n=5$ ) while others were immediately implanted with subcutaneous Silastic capsules filled with testosterone (4androsten-17ß-ol-3-one; Steraloids; $3.18 \mathrm{~mm}$ O.D., $1.57 \mathrm{~mm}$ I.D., $45 \mathrm{~mm}$ long; morphology studies, $\mathrm{n}=6$; electrophysiology studies, $\mathrm{n}=5$ ). Such implants produce plasma titers of testosterone in the high-normal physiological range (Smith et al., 1977), and have previously been demonstrated to reduce motoneuron atrophy induced by the death of nearby motoneurons in the SNB (Fargo and Sengelaub, 2004a,b, 2007). Animals in both saporininjected groups were allowed to survive for four weeks following saporin injection, a length of time sufficient to observe saporin-induced effects on morphology (Fargo and Sengelaub, 2004a,b, 2007). Additional groups of age-matched, untreated males served as normal controls (morphology studies, $\mathrm{n}=5$; electrophysiology studies, $\mathrm{n}=5$ ).

\section{Motoneuron morphology}

Four weeks after saporin injection, animals were re-anesthetized, and the left vastus lateralis muscle (ipsilateral to the saporin-injected vastus medialis muscle in saporin animals) was exposed and injected with horseradish peroxidase conjugated to the cholera toxin B subunit (BHRP; $2 \mu 1,0.2 \%$; List Biological, Inc.). BHRP labeling permits population-level quantitative analysis of motoneuron somal and dendritic morphologies (Goldstein et al., 1990; Kurz et al., 1986). Forty-eight hours after BHRP injection, a period that ensures optimal labeling of motoneurons (Goldstein et al., 1990; Kurz et al., 1986), animals were weighed, overdosed with urethane (approximately $0.25 \mathrm{~g} / 100 \mathrm{~g}$ body weight), and perfused intracardially with saline followed by cold fixative (1\% paraformaldehyde $1.25 \%$ glutaraldehyde). To confirm the specificity of the saporin injections, the vastus lateralis and vastus medialis muscles were removed bilaterally immediately after perfusion and weighed. The lumbar portion of the spinal cord of each animal was removed, postfixed in the same 
fixative for 5 hours, and then transferred to sucrose phosphate buffer (10\% w/v, $\mathrm{pH} 7.4)$ overnight for cryoprotection. Spinal cords were then embedded in gelatin and frozensectioned transversely at $40 \mu \mathrm{m}$; all sections were collected into four alternate series. One series was stained with thionin for use in cell counts. For visualization of BHRP, the three remaining series were immediately reacted using a modified tetramethyl benzidine protocol (Mesulam, 1982), mounted on gelatin-coated slides, and counterstained with thionin.

Motoneuron counts-Motoneurons innervating the quadriceps muscles do not form a discrete nucleus, but instead are contained within the large continuous populations of motoneurons located within the lateral motor column. Thus, to identify the appropriate area within the lateral motor column for motoneuron counts in the unreacted series, we used a method similar to that of Osborne et al. (2007). Briefly, for each animal the range of sections in which motoneurons labeled with BHRP after injection into the vastus lateralis muscle were present in the reacted series was identified, and then motoneuron counts were performed in the appropriate matching sections in the unreacted series. For each animal, estimates of the total number of motoneurons in the left and right lateral motor columns were obtained using the optical disector method outlined by Coggeshall (1992) and a procedure similar to that of West and Gundersen (1990). Counts were made at 937.5X under brightfield illumination. Quadriceps motoneurons are easily recognizable as large, darkly staining, multipolar cells. A three-dimensional counting frame was moved systematically throughout the lateral motor columns in each section within the identified range, and only motoneurons in which there was a clear nucleus and nucleolus were counted, provided they did not contact the forbidden lines of the counting frame; motoneuron nucleoli were counted as they first appeared in focus while focusing through the $\mathrm{z}$ axis, and nucleoli in the first focal plane (i.e., "tops") were not counted. The length of the disector was approximately 25 $\mu \mathrm{m}$, which was adequate for visualizing nucleoli in multiple focal planes. Motoneuron counts were derived from a mean of 15.8 sections spaced $160 \mu \mathrm{m}$ apart and distributed uniformly through the entire rostrocaudal extent of the quadriceps motoneuron pool range. Cell counts for each animal were multiplied by four to correct for the proportion of sections sampled, and then expressed as a ratio (motoneuron number on the saporin-injected side relative to that on the untreated side) to quantify the magnitude of motoneuron depletion.

Using similar methods, the number of BHRP-filled motoneurons was assessed in all sections of the reacted series through the entire rostrocaudal extent of their distribution for all animals. Counts of labeled quadriceps motoneurons were made under brightfield illumination, where somata could be visualized and cytoplasmic inclusion of BHRP reaction product confirmed.

Soma size-The size of quadriceps motoneuron somata was assessed in at least one set of alternate sections (160 $\mu \mathrm{m}$ apart) by measuring the cross-sectional area of BHRP-filled motoneurons. Soma areas of an average of 21.7 motoneurons were measured for each animal using a video-based morphometry system (Stereo Investigator; MicroBrightField) at a final magnification of 780X. Soma areas within each animal were then averaged for statistical analysis.

Dendritic length-For each animal, dendritic lengths in a single representative set of alternate sections were measured under darkfield illumination. Beginning with the first section in which BHRP-labeled fibers were present, labeling through the entire rostrocaudal extent of the quadriceps motoneuron dendritic field was assessed in every third section (480 $\mu \mathrm{m}$ apart) in three dimensions using a computer-based morphometry system (Neurolucida; MicroBrightField) at a final magnification of 250X. Average dendritic length per labeled motoneuron was estimated by summing the measured dendritic lengths of the series of sections, multiplying by three to correct for sampling, then dividing by the total number of 
labeled motoneurons in that series. This method does not attempt to assess the actual total dendritic length of labeled motoneurons (Kurz et al., 1991), but has been shown to be a sensitive and reliable indicator of changes in dendritic morphology in normal development (Goldstein et al., 1993; Goldstein et al., 1990; Goldstein and Sengelaub, 1993), in response to hormonal manipulation (Burke et al., 1999; Burke et al., 1997; Forger and Breedlove, 1987; Goldstein et al., 1990; Goldstein and Sengelaub, 1993; Goldstein and Sengelaub, 1994; Hebbeler and Sengelaub, 2003; Hebbeler et al., 2001; Hebbeler et al., 2002; Kurz et al., 1991; Kurz et al., 1986), after changes in dendritic interactions (Goldstein et al., 1993) and afferent input (Hebbeler and Sengelaub, 2003; Hebbeler et al., 2002; Kalb, 1994), and after the death of nearby motoneurons (Fargo and Sengelaub, 2004a,b, 2007).

Dendritic distribution-To assess potential redistributions of dendrites across treatment groups, for each animal the composite dendritic arbor created in the length analysis was divided using a set of axes oriented radially around the center of the collective labeled somata. These axes divided the spinal cord into twelve bins of $30^{\circ}$ each. The portion of each animal's dendritic arbor per labeled motoneuron contained within each location was then determined. This method provides a sensitive measure of dendritic redistribution in response to changes in dendritic interactions (Goldstein et al., 1993) and afferent input (Hebbeler and Sengelaub, 2003; Hebbeler et al., 2002).

Dendritic extent-The comparability of BHRP labeling across groups was assessed by quantifying both the rostrocaudal and the radial extent of quadriceps motoneuron dendritic arbors. The rostrocaudal extent of the dendritic arbor was determined by recording the rostrocaudal distance spanned by quadriceps motoneuron dendrites for each animal. The maximal radial extent of the arbor in the mediolateral plane was also measured for each animal, using the same radial axes and resultant $30^{\circ}$ bins used for the dendritic distribution analysis. For each bin, the linear distance between the center of the quadriceps motor pool and the most distal BHRP-filled process was measured. Radial dendritic extent is independent of overall dendritic length and reflects the maximal linear distance (in the mediolateral plane) of BHRP transport to the most distal dendritic processes.

\section{Peripheral nerve recording}

Peripheral nerve recording was performed using methods similar to that of Foster and Sengelaub (2004). Rats were anesthetized with chloral hydrate $(450 \mathrm{mg} / \mathrm{kg}$ ip, plus incremental doses to maintain areflexia to noxious stimuli) and placed on a $37^{\circ} \mathrm{C}$ heating pad on a spinal stereotaxic base plate. A high thoracic (T2-4) transection was performed to eliminate supraspinal inputs. The skin over the lumbar spinal column was incised and the underlying fascia and muscle were removed to expose the spinous processes of the vertebrae and the proximal portion of the ribs. A vertebrae clamp was affixed to the spinal column at a point just caudal to the articulation of the final rib, and a laminectomy was then performed to expose the lumbar spinal cord. The dura mater was cut and the entire region was bathed in warm mineral oil for the duration of the experiment to prevent desiccation. To stimulate quadriceps motoneurons via their peripheral afferents, the left L2 dorsal root (ipsilateral to the saporin-injected muscle in saporin animals) was carefully isolated, draped over a bipolar hooked platinum/iridium electrode (FHC, model PBCA0750), crushed onto the distal wire with 6-0 suture, and severed distally. The adjacent roots were also severed bilaterally to prevent any activity in the periphery from introducing artifact into the stimulation pattern. The left hind leg was then immobilized and the quadriceps musculature exposed. The femoral nerve was identified where it emerged from under the psoas muscles, and the branch innervating the vastus lateralis muscle was carefully isolated by blunt dissection. The nerve was then draped over a bipolar hook wire electrode (FHC, as above), crushed onto the distal wire with 6-0 suture, and severed distally. The exposed region was then bathed in mineral 
oil, and additional applications were administered periodically throughout recording. A ground wire was attached to the animal's tail. Care was taken to attach both the stimulating and recording electrodes in the same locations in each animal.

Stimulus pulses ( $0.25 \mathrm{msec}$ long, once every 10 seconds) were generated using a stimulator (Grass S48) and passed through a constant current unit (Grass PSIU6E) before entering the stimulating electrode on the L2 dorsal root. A current probe was attached between the stimulating electrode and the constant current unit to record the actual current received by the animal. The signal from the recording electrodes at the quadriceps motor nerve was bandpass filtered (300 Hz-20 kHz) and amplified 1000X (A-M Systems, Model 1700). Signals from both the current probe and the recording electrode were digitized (Instrunet $100 \mathrm{~B}, \mathrm{GWI}$ ) at $10 \mathrm{kHz}$ and recorded using a computer-based analysis system (SuperScope II, GWI). This software then triggered the next stimulation via a custom-made TTL pulse converter. Quadriceps motor nerve activity was recorded for approximately $13 \mathrm{msec}$ before onset of the stimulation (to record background levels of activity) and continued for a total of $100 \mathrm{msec}$. Stimulation intensities were randomly varied between subthreshold and suprathreshold levels for a total of 200 stimulations to fully characterize motoneuron activation. Recording was temporarily suspended about every 33 stimulations and the polarity of current to the stimulating electrode was reversed to prevent buildup of voltage between its wires. Response amplitudes to pairs of low-intensity stimuli were compared throughout the stimulation trials to confirm the viability of the preparation.

Upon completion of recording, animals were killed with an intracardial overdose injection of Nembutal (3 ml). Linear distance between the stimulating and recording electrodes was determined using calipers (average of six measurements). As for the morphological studies, to confirm the specificity of saporin injection the vastus lateralis and vastus medialis muscles were removed bilaterally immediately after overdose and weighed.

Data Analysis-Within each animal, a variety of basic descriptors of motor activation were analyzed for each trace. Background activity (activity during the first $\sim 13 \mathrm{msec}$ prior to the stimulus onset) was examined in all traces. Response latency, the time delay between the onset of the stimulus pulse and the onset of the response, was corrected for the distance between the electrodes; it should be noted that this latency measurement includes at least one synaptic delay, and thus is not a true measure of axonal conduction velocity. Activity spikes that exceeded an arbitrary level of 10 times background within each individual rectified trace were manually counted. Because spikes recorded from the whole nerve can include motoneurons firing in synchrony, or could be influenced by differences in the shape of individual action potentials, they are not equivalent to single motor axon action potentials and do not necessarily reflect differences in the number of motoneurons firing in response to the stimulus. Maximum response amplitudes in each trace were measured in two ways: maximum peak-to-peak amplitude, a reflection of the number of motoneurons active at a single point in time, and maximum area under the curve (see below). Analyses of response latency, activity duration, spike count, and maximum response amplitudes were restricted to traces produced by stimuli in the $90-110 \%$ intensity range (see below). Limiting the analysis to traces produced at or near maximal activity ensures that each animal was assessed at a comparable (high) degree of motoneuron recruitment and minimizes the degree of variability; this is important because individual variability is a common pitfall in peripheral electrophysiology (Mattsson et al., 1984).

Response amplitudes were measured on all traces collected for each animal using the integral of the rectified records, yielding area under the curve measurements that reflect the activation of all motoneurons during the total duration of the trace. Background activity and the stimulus artifact were excluded from area under the curve measurements. After 
measuring response amplitudes for each individual trace, activation curves were generated for each animal. The stimulus intensities that generated the largest area under the curve were reclassified as $100 \%$ and all other stimulus intensities were normalized relative to them. In the event that more than one stimulus intensity produced a maximal response, the smallest of the maximally-effective stimulus intensities was chosen to represent $100 \%$. Normalizing the stimulus intensity is important because individual differences across animals and small differences in electrode placement can create variability within groups (Mattsson et al., 1984). Normalized stimulus intensities for each animal were grouped into incremental bins from subthreshold to supramaximal levels, and the corresponding resultant response amplitudes were averaged within each bin. The normalized stimulus bins and their averaged responses were then plotted in activation curves (normalized stimulus bins on the $\mathrm{X}$ axis, area under the curve on the $\mathrm{Y}$ axis). Activation curves were generated for each animal, and the data were pooled within groups.

All procedures were performed in accordance with the Indiana University Animal Care and Use Guidelines. All data were analyzed by t-tests or analyses of variance (one way or repeated measures as appropriate) followed by post hoc analyses using Fisher's least significant difference (LSD). Digital light micrographs were obtained using an MDS 290 digital camera system (Eastman Kodak Company). Brightness and contrast of these images were adjusted in Adobe Photoshop.

\section{RESULTS}

\section{Morphology}

Muscle Weights-Overall body weight was not affected; animals weighed an average of $413.47 \pm 31.87 \mathrm{~g}$ (Mean \pm SEM) at the end of treatment, and this did not differ between groups $[F(2,14)=0.45, n s]$. However, muscle weights were affected by saporin injection (Fig. 1). In normal males, the weights of the right $(0.63 \pm 0.02 \mathrm{~g})$ and left $(0.66 \pm 0.03 \mathrm{~g})$ vastus medialis muscles were similar. While the weights of the uninjected (right) vastus medialis muscles were not affected $[F(2,14)=0.26, n s]$, unilateral injection of saporin into the left vastus medialis resulted in marked atrophy of the injected musculature across the saporin groups [an average $68.7 \%$ reduction in weight; $F(2,14)=163.68, p<.0001$ ] Compared to normal males, saporin-injected males had vastus medialis weights that were $70.8 \%$ lighter (LSD, $\mathrm{p}<.0001$ ). Treatment with testosterone did not prevent this atrophy (66.6\% reduced; LSD, $p<.0001$ compared to normal males), and the weights of the vastus medialis muscles in the saporin groups did not differ from each other (LSD, $n s$ ).

Notably, the effect of saporin injection on quadriceps weight was specific to the injected muscle. In normal males, the weights of the right $(1.51 \pm 0.08 \mathrm{~g})$ and left $(1.53 \pm 0.04 \mathrm{~g})$ vastus lateralis muscles were similar. In the saporin groups, the weights of the vastus lateralis muscles on the untreated (right) side $(1.59 \pm 0.03 \mathrm{~g}$, saporin-injected males; $1.49 \pm$ $0.06 \mathrm{~g}$, testosterone-treated saporin males) did not differ from those of normal males $[F(2,14)=0.88, n s]$. Most importantly, the weights of the vastus lateralis muscles $(1.61 \pm$ $0.03 \mathrm{~g}$, saporin-injected males; $1.45 \pm 0.06 \mathrm{~g}$, testosterone-treated saporin males) adjacent to the saporin-injected vastus medialis muscles also did not differ across groups $[F(2,14)=$ $3.20, n s]$.

Motoneuron Counts-In normal males, the number of motoneurons within the identified quadriceps range did not differ between the left $(251.2 \pm 14.28)$ and right $(237.6 \pm 24.97)$ motor columns [paired t-test, $\mathrm{t}(4)=0.63, n s$ ]. Motoneuron counts indicated that saporin was effective in inducing partial motoneuron depletion from the quadriceps motor pool (Fig. 2). Injection of saporin into the left vastus medialis muscle resulted in the death of ipsilateral quadriceps motoneurons, significantly reducing the number of motoneurons in the left motor 
column relative to that in the right $[F(2,14)=5.66, p<.05]$. Unilateral injection of saporin into the left vastus medialis muscle resulted in a $21.4 \%$ reduction in the relative number of motoneurons compared to that of normal males (LSD, $p<.02$ ). Treatment with testosterone did not prevent this reduction ( $25.8 \%$ reduced, LSD, $p<.01$ compared to normal males), and the reduced relative number of motoneurons within the quadriceps range did not differ across saporin groups (LSD, $n s$ ).

\section{Motoneuron morphometry}

Injection of BHRP into the left vastus lateralis successfully labeled ipsilateral quadriceps motoneurons in all groups (Fig. 3). The dendritic arbor of quadriceps motoneurons was strictly unilateral, with extensive ramification along the ventrolateral edges of the gray matter and in the lateral funiculus, as well as throughout the ventral horn. An average of $40.94( \pm 3.23)$ motoneurons per animal were labeled with BHRP, and this did not vary across groups $[F(2,14)=1.34, n s]$.

Soma size-Following saporin-induced motoneuron death, surviving nearby quadriceps motoneurons underwent a modest somal atrophy (Fig. 4). Soma areas decreased by an average of $13.8 \%$ in saporin-injected animals $\left(968.08 \pm 70.35 \mu \mathrm{m}^{2}\right)$, and a similar $13.5 \%$ in testosterone-treated saporin animals $\left(971.69 \pm 71.76 \mu \mathrm{m}^{2}\right)$, compared to normal males $\left(1122.84 \pm 56.64 \mu \mathrm{m}^{2}\right)$. However, these small reductions in soma size failed to reach statistical significance $[F(2,14)=1.58, n s]$.

Dendritic length—Following saporin-induced motoneuron death, surviving nearby quadriceps motoneurons underwent marked dendritic atrophy. Dendritic length decreased by $63.7 \%$ (3765.29 $\pm 879.62 \mu \mathrm{m}$ in saporin-injected animals compared to $10357.92 \pm 1053.61$ $\mu \mathrm{m}$ for normal males, LSD, $p<.0001$; overall test for the effect of group on arbor per cell $F(2,14)=14.82, p<.001 ;$ Fig. 4]. However, while dendritic lengths in testosterone-treated saporin animals $(6226.84 \pm 608.71 \mu \mathrm{m})$ were also shorter than those of normal males (LSD, $p<.01$ ), treatment with testosterone attenuated induced dendritic atrophy, with dendritic lengths being reduced by only $39.9 \%$. Compared to saporin males given no supplemental testosterone, testosterone-treated saporin males had dendritic lengths that were $65.4 \%$ longer (LSD, $p<.05)$.

Dendritic length was nonuniform across radial bins, and a repeated-measures ANOVA revealed a significant effect of radial location $[F(11,154)=8.58, p<.0001$; Fig. 5]. Consistent with the results of the arbor per cell analysis, there was also a significant effect of group $[F(2,154)=16.16, p<.001]$. Reductions in dendritic length occurred throughout the radial distribution, ranging from $78.5 \%\left(60^{\circ}\right.$ to $\left.120^{\circ}\right)$ to $38.2 \%\left(180^{\circ}\right.$ to $\left.240^{\circ}\right)$ in saporininjected animals compared to normal males $[F(1,99)=26.19, p<.001]$. Treatment with testosterone attenuated these reductions, ranging from $51.9 \%\left(120^{\circ}\right.$ to $\left.180^{\circ}\right)$ to $26.0 \%\left(300^{\circ}\right.$ to $\left.360^{\circ}\right)$ compared to normal males $[F(1,99)=12.15, p<.01]$. Dendritic lengths per bin in testosterone-treated saporin animals were longer than those of saporin-injected animals $[F(1,110)=6.63, p<.03]$ throughout most of the radial distribution, with increases ranging from $8.1 \%\left(240^{\circ}\right.$ to $\left.300^{\circ}\right)$ to $139.0 \%\left(60^{\circ}\right.$ to $\left.120^{\circ}\right)$.

Dendritic extent-Consistent with the nonuniform dendritic distribution of quadriceps motoneurons apparent in Figure 3, radial dendritic extent differed across bins (Fig. 6), and repeated-measures ANOVA revealed a significant effect of location $[F(11,154)=16.81, p$ $<.0001]$. However, radial dendritic extent did not differ across groups $[F(2,154)=1.90, n s]$. Rostrocaudal dendritic extent also did not differ across groups $[F(2,14)=0.79, n s]$, spanning $3776.00 \pm 546.35 \mu \mathrm{m}$ in normal males, $3760.00 \pm 402.13 \mu \mathrm{m}$ in saporin-injected animals, and $3120.00 \pm 345.02 \mu \mathrm{m}$ in testosterone-treated saporin animals. 


\section{Electrophysiology}

Muscle Weights-The pattern of results was similar to that reported for the morphology studies. There were no differences in overall body weight; animals weighed an average of $398.87 \pm 32.21 \mathrm{~g}$ at the end of treatment, with no differences between groups $[F(2,12)=$ $1.84, n s]$. However, muscle weights were affected by saporin injection (Fig. 7). In normal males, the weights of the right $(0.64 \pm 0.04 \mathrm{~g})$ and left $(0.65 \pm 0.04 \mathrm{~g})$ vastus medialis muscles were similar. While the weights of the uninjected (right) vastus medialis muscles were not affected $[F(2,12)=2.06, n s]$, unilateral injection of saporin into the left vastus medialis resulted in marked atrophy of the injected musculature across the saporin groups [an average $72.38 \%$ reduction in weight; $F(2,12)=38.53, p<.0001$ ]. Compared to normal males, saporin-injected males had vastus medialis weights that were $70.7 \%$ lighter (LSD, $\mathrm{p}<.0001)$. Treatment with testosterone did not prevent this atrophy $74.07 \%$ reduced; LSD, $p<.0001$ compared to normal males), and the weights of the vastus medialis muscles in the saporin groups did not differ from each other (LSD, $n s$ ).

As found in the morphology studies, the effect of saporin injection on quadriceps weight was again specific to the injected muscle. In normal males, the weights of the right $(1.59 \pm$ $0.05 \mathrm{~g})$ and left $(1.56 \pm 0.11 \mathrm{~g})$ vastus lateralis muscles were similar. In the saporin groups, the weights of the vastus lateralis muscles on the untreated (right) side $(1.35 \pm 0.12 \mathrm{~g}$, saporin-injected males; $1.34 \pm 0.05 \mathrm{~g}$, testosterone-treated saporin males) did not differ from those of normal males $[F(2,12)=3.15, n s]$. Most importantly, the weights of the vastus lateralis muscles $(1.34 \pm 0.08 \mathrm{~g}$, saporin-injected males; $1.27 \pm 0.06 \mathrm{~g}$, testosterone-treated saporin males) adjacent to the saporin-injected vastus medialis muscles also did not differ across groups $[F(2,12)=3.17, n s]$.

Motor activation-Stimulation of the L2 dorsal root afferents to the quadriceps motoneurons resulted in a brief burst of activity in the ipsilateral branch of the femoral nerve innervating the vastus lateralis muscle approximately five milliseconds after the onset of the stimulus pulse. The activity typically consisted of several spikes of varying amplitudes and continued approximately 3-7milliseconds, returning to background levels for the remainder of the 100-ms recording period (see inset, Fig. 8).

Table 1 presents several basic descriptors of the motor activation seen in the femoral nerve. No differences were seen in either the level of background activity present prior to the delivery of the stimulus pulse $[F(2,12)=1.17, n s]$ or in response latency $[F(2,12)=0.60$, $n s]$. However, several differences in the pattern of activation were present between groups. Following saporin-induced motoneuron death, activity produced by surviving quadriceps motoneurons was markedly reduced. Maximum response amplitudes in saporin-injected animals were reduced compared to those of normal males, measured as either maximum peak-to-peak amplitude $(70.5 \%)$ or maximum area under the curve $(62.7 \%),[F \mathrm{~s}(2,12)>$ 5.20, $\mathrm{p}<.03$; LSDs, $p<.03]$. Treatment with testosterone attenuated these reductions; maximum peak-to-peak amplitude was elevated $127.5 \%$, and maximum area under the curve was elevated $172.2 \%$, compared to those of saporin-injected animals. Neither of these parameters in testosterone-treated saporin animals differed from those of normal males (LSDs, $n s)$. Interestingly, increases in both the duration of activity $(118.9 \%)$ and the total number of spikes $(191.5 \%)$ were seen in saporin-injected animals compared to those of normal males $[F \mathrm{~s}(2,12)>5.42, p<.03$; LSDs, $p<.01]$. Treatment with testosterone prevented the saporin-induced increase in activity duration (compared to that of normal males; LSD, $n s)$, and activity duration was significantly shorter than that of saporin-injected animals (LSD, $p<.05$ ). In contrast, testosterone treatment had no effect on the total number of spikes, which remained elevated compared to those of normal males (133.1\%; LSD, $p<$. 05 ) and did not differ from those seen in saporin-injected animals (LSD, $n s$ ). 
Response amplitude measured as area under the curve was also examined across stimulus intensities (Fig. 8). As expected, area under the curve values increased significantly with stimulus intensity $[F(12,144)=34.72, p<.0001]$. Consistent with the reductions in maximum response amplitudes seen in saporin-injected animals, a significant effect of group was also present across stimulus intensities $[F(2,144)=6.80, p<.02]$. Response amplitudes of quadriceps motoneurons were significantly reduced across stimulus intensities in saporininjected animals compared to those of normal males $[F(1,96)=12.21, p<.01]$, with a significant interaction between group and stimulus intensity $[F(12,96)=10.13, p<.0001]$. While low levels of stimulus intensity produced no responses across groups, response amplitudes produced by stimuli above $70 \%$ of the maximally effective stimulus were significantly lower (an average of 67.6\%) in saporin-injected animals compared to those of normal males $[F \mathrm{~s}(1,8)>8.25, p \mathrm{~s}<.03]$. Similar to the effects found with dendritic length, while response amplitudes were reduced across stimulus intensities in testosterone-treated saporin animals compared to those of normal males, these deficits in response amplitude were attenuated. While there was no overall difference in area under the curve values across stimuli between testosterone-treated saporin animals compared to those of normal males $[F(1,96)=4.15, n s]$, there was a significant interaction between group and stimulus intensity $[F(12,96)=2.48, p<.01]$. Response amplitudes produced by stimuli between $71 \%$ and $100 \%$ of the maximally effective stimulus were significantly lower (an average of $52.8 \%$ ) in testosterone-treated saporin animals compared to those of normal males $[F \mathrm{~s}(1,8)>6.72, p \mathrm{~s}$ $<.05]$. Compared to saporin males given no supplemental testosterone, testosterone-treated saporin males had greater response amplitudes across stimulus intensities. While there was no overall difference in area under the curve values across stimuli between saporin-injected animals compared to those of testosterone-treated saporin animals $[F(1,96)=2.92, n s]$, there was a significant interaction between group and stimulus intensity $[F(12,96)=6.19, p<$. 0001]. Response amplitudes produced by stimuli between $91 \%$ and $120 \%$ of the maximally effective stimulus were significantly higher (an average of $119.2 \%$ ) in testosterone-treated saporin animals compared to those of saporin-injected animals $[F \mathrm{~s}(1,8)>5.90, p \mathrm{~s}<.05]$.

\section{DISCUSSION}

Testosterone treatment protects highly androgen sensitive motoneurons from atrophy, and from concomitant reductions in excitability, resulting from the death of nearby motoneurons (Fargo and Sengelaub, 2004a,b, 2005, 2007). In this experiment we tested whether the more typical somatic motoneurons that innervate the quadriceps muscles show similar effects of androgen treatment in attenuating dendritic atrophy and concomitant deficits in function after induced motoneuron depletion. Partial motoneuron depletion resulted in decreased dendritic length and deficits in activation in remaining quadriceps motoneurons. Importantly, testosterone treatment attenuated dendritic atrophy and reductions in motor activation, indicating that the neuroprotective effects of testosterone we have previously reported appear to be common across diverse motoneuron populations.

\section{Muscle Weights}

In both the morphology and electrophysiology studies saporin injection decreased the weight of the injected vastus medialis muscle, but had no effect on the weight of the adjacent uninjected vastus lateralis muscle (Figs. 1, 7). These results are comparable to previous findings (Fargo and Sengelaub, 2004a,b;2007) and indicate that saporin treatments were both effective and confined to the targeted musculature. Also consistent with these previous findings, treatment with testosterone did not prevent the reduction in muscle weight resulting from saporin injection; the weights of the vastus medialis muscles in the saporininjected groups did not differ, being reduced by approximately $70 \%$. However, in contrast with our previous work, treatment with testosterone had no effect on the weight of the non- 
saporin-injected vastus lateralis muscles, either those adjacent to the saporin-injected muscle or in the contralateral limb. Because the weight of the contralateral vastus lateralis muscles was not affected by testosterone treatment, the lack of an androgen effect on the muscles adjacent to the saporin-injected muscles cannot be ascribed to an inhibition of an anabolic effect of testosterone by saporin. In our previous studies, wherein we utilized the highly androgen sensitive SNB neuromuscular system (Fargo and Sengelaub, 2004a,b;2007), testosterone treatment increased the size of the non-saporin-injected adjacent perineal musculature by approximately $20 \%$. Although androgens are known to have protein anabolic effects on general skeletal muscle tissue (Kochakian, 1975), these effects are small compared to those observed in the perineal muscles (Kochakian et al., 1956;Wainman and Shipounoff, 1941). This, combined with the modest supplemental testosterone treatment we used in the current study, makes the lack of effect of testosterone on quadriceps muscle weight unsurprising. However, the absence of an effect of testosterone treatment on muscle weight despite a positive effect on dendritic length (see below) begins to address a potential mechanism of the neuroprotective effects of testosterone treatment. We have previously speculated that the hypertrophy in perineal muscle weight produced by exogenous testosterone treatment could potentially provide an enhanced neurotrophic support to remaining SNB motoneurons, attenuating dendritic atrophy (Fargo and Sengelaub, 2004a,b). Given that we saw no such testosterone-induced hypertrophy in the current study, but dendritic atrophy in remaining quadriceps motoneurons was nonetheless attenuated by testosterone treatment, it is unlikely that any potential neurotrophic support is dependent on muscle size alone.

\section{Motoneuron Counts}

Saporin injection into only one of the four muscles comprising the quadriceps resulted in the death of ipsilateral motoneurons, reducing the number in the quadriceps pool by approximately $24 \%$ across both saporin-injected groups (Fig. 2). This induced death appears to have been specific to the motoneurons innervating the saporin-injected vastus medialis muscle, as there were no differences in the number of labeled motoneurons following injection of BHRP into the adjacent vastus lateralis. While steroid hormones have been shown to prevent injury-induced neuron death in other preparations (Ahlbom et al., 2001;Hammond et al., 2001;Huppenbauer et al., 2005;Pike, 2001;Ramsden et al., 2003), they are not effective in preventing saporin-induced motoneuron death in SNB (Fargo and Sengelaub, 2004a,b;2007) or quadriceps motoneurons (current study). Thus, the beneficial effects of steroid treatment on the morphology of nearby surviving motoneurons cannot be attributed to a hormone-mediated attenuation of the ability of saporin to kill motoneurons.

\section{Morphometry}

Somata-After the death of motoneurons by saporin injection, the cross-sectional area of surviving nearby quadriceps motoneurons was reduced by about $14 \%$ (Fig. 4). This reduction in size is comparable to what we have observed previously (approximately 18\%; Fargo and Sengelaub, 2004a,b;2007), but in the current study it did not reach statistical significance. Interestingly, this reduction was similar across saporin groups, and thus stands in contrast to previous reports in which treatment with testosterone attenuated induced somal atrophy following partial motoneuron depletion (Fargo and Sengelaub, 2004b;2007). This lack of effect of testosterone treatment is similar to what we observed in quadriceps muscle weight, and likely reflects a lower androgen sensitivity in this neuromuscular system (see below). For example, while castration results in dramatic reductions in the size of SNB motoneuron somata (up to $45 \%$ ) which can be reversed with testosterone treatment (Kurz et al., 1986), castration with or without hormone replacement has no effect on soma size in quadriceps motoneurons (Osborne et al., 2007). 


\section{Dendrites}

Saporin-induced motoneuron death resulted in a pronounced dendritic atrophy in surviving nearby quadriceps motoneurons. Dendritic length of quadriceps motoneurons decreased by almost 64\% in saporin-injected animals (Figs. 3, 4), a magnitude of atrophy almost identical to that seen in SNB motoneurons (Fargo and Sengelaub, 2004a,b;2007). This reduction was not restricted to any specific portion of the dendritic distribution (Fig. 5), suggesting that the effect was the result of a general effect on the quadriceps motoneurons rather than a loss of a specific afferent population (Hebbeler and Sengelaub, 2003). Also similar to our previous reports for SNB motoneurons, atrophy of quadriceps motoneuron dendrites was attenuated in testosterone-treated saporin animals, but in the present case to a lesser degree. In the $\mathrm{SNB}$, testosterone treatment attenuated dendritic atrophy, resulting in dendritic lengths that were reduced an average of only approximately $16 \%$ from normal lengths, and were greater than those of saporin-injected animals by an average of over 119\% (Fargo and Sengelaub, 2004a,b;2007). In contrast, quadriceps motoneurons in testosterone-treated saporin animals had dendritic lengths that were reduced almost $40 \%$ from normal lengths, and were greater than those of saporin-injected animals by only approximately $65 \%$.

Given that spinal motoneurons and their target muscles contain androgen receptors (Michel and Baulieu, 1974; Kochakian, 1975; Breedlove and Arnold, 1980, 1883; Matsuura et al., 1993; Lumbroso et al., 1996), we hypothesized that the quadriceps system would show neuroprotective effects of testosterone. Androgenic effects in typical somatic motoneurons have been demonstrated previously. For example, following axotomy of the sciatic nerve, testosterone increases axonal regeneration rates (Kujawa et al., 1993), and this effect is accompanied by enhanced $\beta$-tubulin expression in sciatic motoneurons (Brown et al., 2001). Similarly, the frequency of trkB receptor-immunolabeled quadriceps motoneurons responds to changes in androgen levels (Osborne et al., 2007). In the current study, while testosterone treatment was effective in attenuating dendritic atrophy in quadriceps motoneurons, it did not protect them to the same degree as previously observed in the highly steroid-sensitive SNB. A likely explanation for this difference lies in the expression of androgen receptors in these two systems. SNB motoneurons abundantly express androgen receptors, and almost $70 \%$ of SNB motoneurons are labeled at $5 \mathrm{X}$ background; in contrast, less than $3 \%$ reach this criterion in other motoneurons (Breedlove and Arnold, 1980, 1883). Using steroid autoradiography, we have found that while quadriceps motoneurons are labeled significantly above background levels with tritiated testosterone, SNB motoneurons accumulate testosterone at almost three times the density seen in quadriceps motoneurons (Huguenard and Sengelaub, unpublished results). Similarly, the principal SNB target muscles in males (the bulbocavernosus and levator ani muscles) are enriched for androgen binding sites and androgen receptor protein compared to other striated muscles (Dube et al., 1976; Tremblay et al., 1977; Monks et al., 2006). Androgen receptor protein is present in substantially higher concentrations in the levator ani compared to other skeletal muscle (Monks et al., 2006), and the bulbocavernosus and levator ani muscles have over four times as many binding sites for testosterone than are present in the quadriceps muscles (Dube et al., 1976). Thus, as differences in the density of androgen receptors are thought to underlie differences in androgen responsiveness across tissues (Monks et al., 2006), the lower density of androgen receptors in the quadriceps system might result in a smaller protective effect of testosterone.

Previous studies have demonstrated that neither axonal transport of BHRP (Leslie et al., 1991) nor dendritic transport as demonstrated by the rostrocaudal or radial extent of dendritic labeling (Fargo and Sengelaub, 2004b; Goldstein and Sengelaub, 1994; Hebbeler et al., 2002; Kurz et al., 1991) are affected by hormone levels. Thus, in the present study, we believe that the differences we observed across treatment groups reflect true dendritic atrophy in surviving motoneurons in saporin-injected animals, which is attenuated by treatment with androgens. The possibility that confounds arising from saporin injection 
could affect retrograde transport is also an important consideration, as such an artifact could potentially result in apparent alterations in dendritic morphology. However, no differences in either radial or rostrocaudal extents of quadriceps motoneuron dendrites in the saporin groups compared to normal values were observed. Therefore, we believe that the dendritic labeling across groups was comparable and that the shorter dendritic lengths we observed in saporin groups reflect true dendritic atrophy.

\section{Functional correlates}

Previous work has demonstrated that despite the absence of direct injury, the electrophysiological properties of remaining (uninjured) motoneurons are altered, for example reducing conduction velocity and prolonging afterhyperpolarization (Havton et al., 2001). Alterations in central connectivity consequent to dendritic changes are also apparent electrophysiologically (Kuno and Llinás, 1970; Sernagor et al., 1986). In related studies, we have found that regressive changes in motoneuron morphology are correlated with changes in motor activation: concomitant with dendritic atrophy, activation of motoneurons is attenuated, and this change is prevented or reversed with androgen treatment, providing a functional measure of recovery (Fargo et al., 2003; Fargo and Sengelaub, 2005).

Following saporin-induced motoneuron death, the atrophy described above in the morphology of remaining quadriceps motoneurons was accompanied by marked reductions in stimulation-evoked activation. In saporin-injected animals, stimulation of the dorsal root afferents to the quadriceps motoneurons produced responses in the peripheral nerve whose amplitudes were dramatically reduced compared to those of normal males (Table 1; Fig. 8). These reductions were seen in both maximum peak-to-peak amplitude (likely reflecting fewer quadriceps motoneurons activated simultaneously) as well as area under the curve measures (likely reflecting fewer motoneurons activated during the total duration of the trace). Significantly reduced amplitudes were consistently observed in saporin-injected animals in response to stimuli above $70 \%$ of the maximally effective stimulus, intensities that produced robust responses in normal males. While response amplitudes were reduced in saporin-injected animals, the duration of evoked activity was longer, with a greater number of observed spikes (Table 1), potentially reflecting a loss of synchronous firing in response to afferent stimulation in the remaining quadriceps motoneurons.

Just as the atrophy in the morphology of quadriceps motoneuron dendrites was attenuated in testosterone-treated saporin animals, deficits in response amplitude were also attenuated with testosterone treatment. While deficits were still present at lower stimulus intensities, at the highest intensities response amplitudes in testosterone-treated saporin animals were similar to those of normal males, and significantly greater than those of saporin-treated animals (Fig. 8). Treatment with testosterone also attenuated the increase in evoked activity duration, but had no effect on the increase in the total number of spikes.

Importantly, the methodology used here was not intended to address the mechanisms of the regressive changes in excitability, but rather only serves to provide a measure of functional recovery. Measures of functional recovery are important components in assessing the efficacy of any treatment strategy. For example, following facial nerve axotomy, animals exhibit loss of eyeblink, vibrissae movement, and abnormal vibrissae orientation. As the facial nerve regenerates, these gradually and sequentially return until recovery is complete, providing a measure of functional recovery (Kujawa et al., 1989; Tanzer and Jones, 2004). Similarly, in spinal cord injury models, gross locomotor recovery is typically assessed using behavioral analyses (e.g., Basso-Beattie-Breshnahan locomotor rating scale, Basso et al., 1995; Jones et al., 2004; inclined plane task, Rivlin and Tator, 1977; Midha et al., 1987). In the present study, the deficits in quadriceps motor activation, and their attenuation with 
testosterone treatment, corresponded directly to the morphological changes in quadriceps motoneurons, confirming that the neuroprotective effects of testosterone are truly functional.

\section{Neuroprotective effects of testosterone}

Androgens have been shown to have powerful neuroprotective effects in a variety of systems. For example, testosterone protects against cell death in cultured hippocampal neurons (Pike, 2001), prevents injury-induced dendritic atrophy in cortical pyramidal cells (Forgie and Kolb, 2003), promotes earlier functional recovery after stroke (Pan et al., 2004), and stimulates motoneuron axonal growth after peripheral nerve injury (Kujawa et al., 1989). The mechanisms through which androgens act are multiple, and include attenuation of synaptic stripping (Jones et al., 1997b) and injury-induced upregulation of GFAP (Coers et al., 2002; Jones et al., 1997c), mediation of the central glial response (Jones et al., 1999a), and enhancement of the ribosomal response (Kinderman and Jones, 1993). The expression of multiple proteins involved in structural plasticity has also been shown to be androgensensitive, including enhanced expression of the cytoskeletal proteins $\beta$-tubulin (Jones and Oblinger, 1994; Jones et al., 1999b; Brown et al., 2001; Matsumoto et al., 1994) and GAP-43 (Coers et al., 2002; Jones et al., 1997a), and elevated neuritin mRNA expression (Fargo et al., 2008). Similarly, proteins thought to be involved in neuroprotection are also regulated by androgens, including increased expression of heat shock protein (Zhang et al., 2004; Tetzlaff et al., 2007), proteins with antioxidant functions (e.g., catalase, Ahlbom et al., 2001), and the neurotrophin BDNF (Ottem et al., 2007) and its receptor trkB (Osborne et al., 2007). Androgens are also thought to be involved with the activation of signaling pathways involved in neuroprotection (e.g., MAPK/ERK, Pike et al., 2008). Establishing which of these mechanisms, proteins, and pathways are involved in the androgen-mediated protection of motoneuron dendrites from injury-induced atrophy will be valuable contributions to establishing new neurotherapeutic strategies.

\section{Conclusions}

Androgens are already known to prevent or reduce motoneuron death in several experimental paradigms (Ahlbom et al., 2001; Hammond et al., 2001; Huppenbauer et al., 2005; Pike, 2001; Ramsden et al., 2003). The present results indicate that androgens are also capable of attenuating secondary atrophy and loss of function in surviving nearby motoneurons, not only in highly androgen-sensitive motoneurons, but in more typical motoneuron populations as well, further supporting a role for testosterone as a neurotherapeutic agent in the injured nervous system.

\section{Acknowledgments}

We wish to thank Dr. Cara L. Wellman and Tom Verhovshek for their helpful comments on the manuscript. This work was supported by NIH-NINDS NS047264 to D.R.S.

\section{References}

Ahlbom E, Prins GS, Ceccatelli S. Testosterone protects cerebellar granule cells from oxidative stressinduced cell death through a receptor mediated mechanism. Brain Res. 2001; 892:255-262. [PubMed: 11172772]

Al-Majed AA, Brushart TM, Gordon T. Electrical stimulation accelerates and increases expression of BDNF and trkB rnRNA in regenerating rat femoral motoneurons. Eur J Neurosci. 2000; 12:43814390. [PubMed: 11122348]

Basso DM, Beattie M, Bresnahan JC. A sensitive and reliable locomotor rating scale for open field testing in rats. J Neurotrauma. 1995; 12:1-21. [PubMed: 7783230]

Bisby MA, Tetzlaff W. Changes in cytoskeletal protein synthesis following axon injury and during regeneration. Mol Neurobiol. 1992; 6:107-123. [PubMed: 1476674] 
Brännström T, Havton L, Kellerth J-O. Changes in size and dendritic arborization patterns of adult cat spinal a-motoneurons following permanent axotomy. J Comp Neurol. 1992; 318:439-451.

[PubMed: 1578011]

Breedlove SM, Arnold AP. Hormone accumulation in a sexually dimorphic motor nucleus of the rat spinal cord. Science. 1980; 210:564-566. [PubMed: 7423210]

Breedlove SM, Arnold AP. Sex differences in the pattern of steroid accumulation by motoneurons of the rat lumbar spinal cord. J Comp Neurol. 1983; 215:211-216. [PubMed: 6853774]

Brown TJ, Storer P, Oblinger M, Jones KJ. Androgenic enhancement of $\beta_{\mathrm{II}^{-}}$-tubulin mRNA in spinal motoneurons following sciatic nerve injury. Rest Neurol Neurosci. 2001; 18:191-198.

Brushart TM, Seiler WA. Selective reinnervation of distal motor stumps by peripheral axons. Exp Neurol. 1987; 97:290-300.

Burke KA, Kuwajima M, Sengelaub DR. Aromatase inhibition reduces dendritic growth in a sexually dimorphic rat spinal nucleus. J Neurobiol. 1999; 38:301-312. [PubMed: 10022574]

Burke KA, Widows MR, Sengelaub DR. Synergistic effects of testosterone metabolites on the development of motoneuron morphology in a sexually dimorphic rat spinal nucleus. J Neurobiol. 1997; 33:1-10. [PubMed: 9212065]

Cleveland DW, Rothstein JD. From Charcot to Lou Gehrig: Deciphering selective motor neuron death in ALS. Nat Rev Neurosci. 2001; 2:806-819. [PubMed: 11715057]

Coers S, Tanzer L, Jones KJ. Testosterone treatment attenuates the effects of facial nerve transection on glial fibrillary acidic protein (GFAP) levels in the hamster facial motor nucleus. Metab Brain Dis. 2002; 17:55-63. [PubMed: 12083337]

Coggeshall RE. A consideration of neural counting methods. Trends in Neurosci. 1992; 15:9-13.

Dubé JY, Lesage R, Tremblay RR. Androgen and estrogen binding in rat skeletal and perineal muscles. Can J Biochem. 1976; 54:50-55. [PubMed: 175903]

Fargo KN, Alexander TD, Tanzer L, Poletti A, Jones KJ. Androgen regulates neuritin mRNA in an in vivo model of steroid-enhanced peripheral nerve regeneration. J Neurotrauma. 2008; 25:561-566. [PubMed: 18419250]

Fargo KN, Foster AM, Harty MW, Sengelaub DR. Estrogen alters excitability but not morphology of a sexually dimorphic neuromuscular system in adult rats. J Neurobiol. 2003; 56:66-77. [PubMed: 12767033]

Fargo KN, Sengelaub DR. Testosterone manipulation protects motoneurons from dendritic atrophy after contralateral motoneuron depletion. J Comp Neurol. 2004a; 469:96-106. [PubMed: 14689475]

Fargo KN, Sengelaub DR. Exogenous testosterone prevents motoneuron atrophy induced by contralateral motoneuron depletion. J Neurobiol. 2004b; 60:348-359. [PubMed: 15281072]

Fargo, KN.; Sengelaub, DR. Program No. 672.8. 2005 Society for Neuroscience Abstracts Viewer/ Itinerary Planner. 2005. Testosterone treatment prevents deficits in motor activation caused by partial loss of motoneurons.

Fargo KN, Sengelaub DR. Androgenic, but not estrogenic, protection of motoneurons from somal and dendritic atrophy induced by the death of neighboring motoneurons. Dev Neurobiol. 2007; 67:1094-1106. [PubMed: 17565709]

Forger NG, Breedlove SM. Seasonal variation in mammalian striated muscle mass and motoneuron morphology. J Neurobiol. 1987; 18:155-165. [PubMed: 3572390]

Forgie ML, Kolb B. Manipulation of gonadal hormones in neonatal rats alters the morphological response of cortical neurons to brain injury in adulthood. Behav Neurosci. 2003; 117:257-262. [PubMed: 12708522]

Foster AM, Sengelaub DR. Bilateral organization of unilaterally-generated activity in lumbar spinal motoneurons of the rat. Brain Res. 2004; 1009:98-109. [PubMed: 15120587]

Goldstein LA, Kurz EM, Kalkbrenner AE, Sengelaub DR. Changes in dendritic morphology of rat spinal motoneurons during development and after unilateral target deletion. Dev Brain Res. 1993; 73:151-163. [PubMed: 8353928]

Goldstein LA, Kurz EM, Sengelaub DR. Androgen regulation of dendritic growth and retraction in the development of a sexually dimorphic spinal nucleus. J Neurosci. 1990; 10:935-946. [PubMed: 2319307] 
Goldstein LA, Sengelaub DR. Motoneuron morphology in the dorsolateral nucleus of the rat spinal cord: normal development and androgenic regulation. J Comp Neurol. 1993; 338:588-600. [PubMed: 7510730]

Goldstein LA, Sengelaub DR. Differential effects of dihydrotestosterone and estrogen on the development of motoneuron morphology in a sexually dimorphic rat spinal nucleus. J Neurobiol. 1994; 25:878-892. [PubMed: 8089663]

Hammond J, Le Q, Goodyer C, Gelfand M, Trifiro M, LeBlanc A. Testosterone-mediated neuroprotection through the androgen receptor in human primary neurons. J Neurochem. 2001; 77:1319-1326. [PubMed: 11389183]

Havton LA, Hotson JR, Kellerth J. Partial peripheral motor nerve lesions induce changes in the conduction properties of remaining intact motoneurons. Muscle Nerve. 2001; 24:662-666. [PubMed: 11317276]

Hebbeler SL, Sengelaub DR. Development of a sexually dimorphic neuromuscular system in male rats after spinal transection: morphologic changes and implications for estrogen sites of action. J Comp Neurol. 2003; 467:80-96. [PubMed: 14574681]

Hebbeler SL, Verhovshek T, Sengelaub DR. Ovariectomy attenuates dendritic growth in hormonesensitive spinal motoneurons. J Neurobiol. 2001; 48:301-314. [PubMed: 11500843]

Hebbeler SL, Verhovshek T, Sengelaub DR. N-methyl-D-aspartate receptor blockade inhibits estrogenic support of dendritic growth in a sexually dimorphic rat spinal nucleus. J Comp Neurol. 2002; 451:142-152. [PubMed: 12209833]

Hebel, R.; Stromberg, MW. Anatomy and Embryology of the Laboratory Rat. BioMed Verlag: Federal Republic of Germany; 1986.

Henderson, VW.; Reynolds, DW. Protective effects of estrogen on aging and damaged neural systems. In: Pfaff, DW.; Arnold, AP.; Etgen, AM.; Fahrbach, SE.; Rubin, RT., editors. Hormones, Brain and Behavior. San Diego: Academic Press; 2002. p. 821-837.

Hoang TX, Nieto J, Tillakaratne NJK, Havton LA. Autonomic and motor neuron death is progressive and parallel in a lumbosacral ventral root avulsion model of cauda equina injury. J Comp Neurol. 2003; 467:477-486. [PubMed: 14624482]

Huppenbauer CB, Tanzer L, DonCarlos LL, Jones KJ. Gonadal steroid attenuation of developing hamster facial motoneuron loss by axotomy: equal efficacy of testosterone, dihydrotestosterone, and 17-beta estradiol. J Neurosci. 2005; 25:4004-4013. [PubMed: 15843602]

Jones KJ. Gonadal steroids as promoting factors in axonal regeneration. Brain Res Bull. 1993; 30:491498. [PubMed: 8457899]

Jones TB, Ankeny DP, Guan Z, McGaughy V, Fisher LC, Basso DM, Popovich PG. Passive or active immunization with myelin basic protein impairs neurological function and exacerbates neuropathology after spinal cord injury in rats. J Neurosci. 2004; 24:3752-3761. [PubMed: 15084655]

Jones KJ, Brown TJ, Damaser M. Neuroprotective effects of gonadal steroids on regenerating peripheral motoneurons. Brain Res Rev. 2001; 37:372-382. [PubMed: 11744101]

Jones KJ, Coers S, Storer PD, Tanzer L, Kinderman NB. Androgenic regulation of the central glia response following nerve damage. J Neurobiol. 1999; 40:560-573. [PubMed: 10453056]

Jones KJ, Drengler SM, Oblinger MM. Gonadal steroid regulation of growth-associated protein GAP-43 mRNA expression in axotomized hamster facial motor neurons. Neurochem Res. 1997a; 22:1367-1374. [PubMed: 9355109]

Jones KJ, Durica TE, Jacob SK. Gonadal steroid preservation of central synaptic input to hamster facial motoneurons following peripheral axotomy. J Neurocytol. 1997b; 26:257-266. [PubMed: 9192291]

Jones KJ, Kinderman NB, Oblinger MM. Alterations in glial fibrillary acidic protein (GFAP) mRNA levels in the hamster facial motor nucleus: effects of axotomy and testosterone. Neurochem Res. 1997c; 22:1359-1366. [PubMed: 9355108]

Jones KJ, Oblinger MM. Androgenic regulation of tubulin gene expression in axotomized hamster facial motoneurons. J Neurosci. 1994; 14:3620-3627. [PubMed: 8207476] 
Jones KJ, Storer PD, Drengler SM, Oblinger MM. Differential regulation of cytoskeletal gene expression in hamster facial motoneurons: Effects of axotomy and testosterone treatment. J Neurosci Res. 1999b; 57:817-823. [PubMed: 10467252]

Kalb RG. Regulation of motor neuron dendrite growth by NMDA receptor activation. Development. 1994; 120:3063-3071. [PubMed: 7720552]

Kennedy WR, Alter M, Sung JH. Progressive proximal spinal and bulbar muscular atrophy of late onset. A sex-linked recessive trait. Neurology. 1968; 18:671-680. [PubMed: 4233749]

Kinderman NB, Jones KJ. Testosterone enhancement of the nerve cell body response to injury: Evidence using in situ hybridization and ribosomal DNA probes. J Neurosci. 1993; 13:1523-1532. [PubMed: 8463832]

Kochakian CD. Definition of androgens and protein anabolic steroids. Pharmac Therap B. 1975; $1: 149-177$.

Kochakian CD, Tillotson C, Austin J. Castration and the growth of muscles in the rat. Endocrinol. 1956; 58:226-231.

Kujawa KA, Emeric E, Jones KJ. Testosterone differentially regulates the regenerative properties of injured hamster facial motoneurons. J Neurosci. 1991; 11:3898-3906. [PubMed: 1744696]

Kujawa KA, Jacob JM, Jones KJ. Testosterone regulation of the regenerative properties of injured rat sciatic motor neurons. J Neurosci Res. 1993; 35:268-273. [PubMed: 8350388]

Kujawa KA, Jones KJ. Testosterone-induced acceleration of recovery from facial paralysis in male hamsters: temporal requirements of hormone exposure. Physiol Behav. 1990; 48:765-768. [PubMed: 2082378]

Kujawa KA, Kinderman NB, Jones KJ. Testosterone-induced acceleration of recovery from facial paralysis following crush axotomy of the facial nerve in male hamsters. Exp Neurol. 1989; 105:80-85. [PubMed: 2744130]

Kuno M, Llinás R. Enhancement of synaptic transmission by dendritic potentials in chromatolysed motoneurons of the cat. J Physiol. 1970; 210:807-821. [PubMed: 4322766]

Kurz EM, Brewer RG, Sengelaub DR. Hormonally mediated plasticity of motoneuron morphology in the adult rat spinal cord: a cholera toxin-HRP study. J Neurobiol. 1991; 22:976-988. [PubMed: 1795161]

Kurz EM, Sengelaub DR, Arnold AP. Androgens regulate the dendritic length of mammalian motoneurons in adulthood. Science. 1986; 232:395-398. [PubMed: 3961488]

Leslie M, Forger NG, Breedlove SM. Does androgen affect axonal transport of cholera toxin HRP in spinal motoneurons? Neurosci Lett. 1991; 126:199-202. [PubMed: 1922934]

Lumbroso S, Sandillon F, Georget V, Lobaccaro JM, Brinkmann AO, Privat A, Sultan C. Immunohistochemical localization and immunoblotting of androgen receptor in spinal neurons of male and female rats. Eur J Endocrinol. 1996; 134:626-632. [PubMed: 8664984]

Matsumoto A, Arai Y, Urano A, Hyodo S. Androgen regulates gene expression of cytoskeletal proteins in adult rat motoneurons. Horm Behav. 1994; 28:357-366. [PubMed: 7729804]

Matsuura T, Ogata A, Demura T, Moriwaka F, Tashiro K, Koyanagi T. Identification of androgen receptor in the rat spinal motoneurons. Immunohistochemical and immunoblotting analyses with monoclonal antibody. Neurosci Lett. 1993; 158:5-8. [PubMed: 8233073]

Mattsson JL, Albee RR, Brandt LM. H-reflex waveform and latency variability in rats. Fund App Toxicol. 1984; 4:944-948.

Mesulam, MM. Tracing Neural Connections with Horseradish Peroxidase. Chichester: Wiley; 1982.

Michel G, Baulieu E. Recepteur cytosoluble des androgens dans un muscle strie squelettique. C R Aca Sci. 1974; 279:421-424.

Midha R, Fehlings MG, Tator CH, Saint-Cyr JA, Guha A. Assessment of spinal cord injury by counting corticospinal and rubrospinal neurons. Brain Res. 1987; 410:299-308. [PubMed: 3594239]

Monks DA, Kopachik W, Breedlove SM, Jordan CL. Anabolic responsiveness of skeletal muscles correlates with androgen receptor protein but not mRNA. Can J Physiol Pharmacol. 2006; 84:272277. 
Moschilla G, Song S, Chakera T. Post-traumatic lumbar nerve root avulsion. Austral Radiol. 2001; 45:281-284.

Nicolopoulos-Stournaras S, Iles JF. Motor neuron columns in the lumbar spinal cord of the rat. J Comp Neurol. 1983; 217:75-85. [PubMed: 6875053]

O'Hanlon GM, Lowrie MB. Nerve injury in adult rats causes abnormalities in the motoneuron dendritic field that differ from those seen following neonatal nerve injury. Exp Brain Res. 1995; 103:243-250. [PubMed: 7789431]

Osborne MC, Verhovshek T, Sengelaub DR. Androgen regulates trkB expression in spinal motoneurons. J Neurosci Res. 2007; 85:303-309. [PubMed: 17131419]

Ottem EN, Beck LA, Jordan CL, Breedlove SM. Androgen-dependent regulation of brain-derived neurotrophic factor and tyrosine kinase $\mathrm{B}$ in the sexually dimorphic spinal nucleus of the bulbocavernosus. Endocrinol. 2007; 1458:3655-3665.

Pan, Y.; Zhang, H.; Acharya, A.; Patrick, PH.; Oliver, D.; Morley, JE. Effect of testosterone on functional recovery in the castrate male rat stroke model. Presented at the annual meeting of the American Neurological Association; Toronto. October 3-6, 2004; 2004.

Pike CJ. Testosterone attenuates $\beta$-amyloid toxicity in cultured hippocampal neurons. Brain Res. 2001; 919:160-165. [PubMed: 11689174]

Pike CJ, Nguyen T-VV, Ramsden M, Yao M, Murphy MP, Rosario ER. Androgen cell signaling pathways involved in neuroprotective actions. Horm Behav. 2008; 53:693-705. [PubMed: 18222446]

Ramsden M, Shin TM, Pike CJ. Androgens modulate neuronal vulnerability to kainite lesion. Neuroscience. 2003; 122:573-578. [PubMed: 14622899]

Rivlin AS, Tator CH. Objective clinical assessment of motor function after experimental spinal cord injury in the rat. J Neurosurg. 1977; 47:577-581. [PubMed: 903810]

Sengelaub, DR.; Osborne, MC.; Little, CM.; Huyck, KD.; Verhovshek, T. Program No. 683.12. 2006 Society for Neuroscience Abstracts Viewer/Itinerary Planner. Neuroprotective effects of testosterone in two models of spinal motoneuron injury.

Sernagor E, Yarom Y, Werman R. Sodium-dependent regenerative responses in dendrites of axotomized motoneurons in the cat. Proc Natl Acad Sci USA. 1986; 83:7966-7970. [PubMed: 2429323]

Smith, ER.; Damassa, DA.; Davidson, JM. Hormone Administration: Peripheral and Intracranial Implants. In: Meyer, RD., editor. Methods in Psychobiology. New York: Academic Press; 1977. p. 259-279.

Standler N, Bernstein JJ. Dendritic alteration of spinal motoneurons after ablation of somatomotor cortex. Exp Neurol. 1984; 83:264-273. [PubMed: 6692867]

Stirpe F, Barbieri L, Battelli MG, Soria M, Lappi DA. Ribosome-inactivating proteins from plants: present status and future prospects. Bio/Technology. 1992; 10:405-412. [PubMed: 1368484]

Stirpe F, Gasperi-Campani A, Barbieri L, Falasca A, Abbondanza A, Stevens WA. Ribosomeinactivating proteins from the seeds of Saponaria officinalis L. (soapwort), of Agrostemma githago L. (corn cockle) and from Asparagus officinalis L. (asparagus), and from the latex of Hura crepitans L. (sandbox tree). Biochem J. 1983; 216:617-625. [PubMed: 6667259]

Sumner BEH, Watson WE. Retraction and expansion of the dendritic tree of motor neurons of adult rats induced in vivo. Nature. 1971; 233:273-275. [PubMed: 4938371]

Tanzer L, Jones KJ. Neurotherapeutic action of testosterone on hamster facial nerve regeneration: temporal window of effects. Horm Behav. 2004; 45:339-344. [PubMed: 15109908]

Tetzlaff J, Tanzer L, Jones KJ. Exogenous androgen treatment delays the stress response following hamster facial nerve injury. J Neuroendocrinol. 2007; 19:383-389. [PubMed: 17425613]

Tremblay RR, Dube JY, Ho-Kim MA, Lesage R. Determination of rat muscles androgen-receptor complexes with methyltrienolone. Steroids. 1977; 29:185-195. [PubMed: 841621]

Titmus MJ, Faber DS. Axotomy-induced alterations in the electrophysiological characteristics of neurons. Prog Neurobiol. 1990; 35:1-51. [PubMed: 2217820]

Wainman P, Shipounoff GC. The effects of castration and testosterone propionate on the striated perineal musculature in the rat. Endocrinol. 1941; 29:975-978. 
West MJ, Gundersen HJG. Unbiased stereological estimation of the number of neurons in the human hippocampus. J Comp Neurol. 1990; 296:1-22. [PubMed: 2358525]

Woolley, CS.; Cohen, RS. Sex steroids and neuronal growth in adulthood. In: Pfaff, DW.; Arnold, AP.; Etgen, AM.; Fahrbach, SE.; Rubin, RT., editors. Hormones, Brain and Behavior. San Diego: Academic Press; 2002. p. 717-777.

Zhang Y, Champagne N, Beitel LK, Goodyer CG, Trifiro M, LeBlanc A. Estrogen and androgen protection of human neurons against intracellular amyloid beta1-42 toxicity through heat shock protein 70. J Neurosci. 2004; 24:5315-5321. [PubMed: 15190103] 

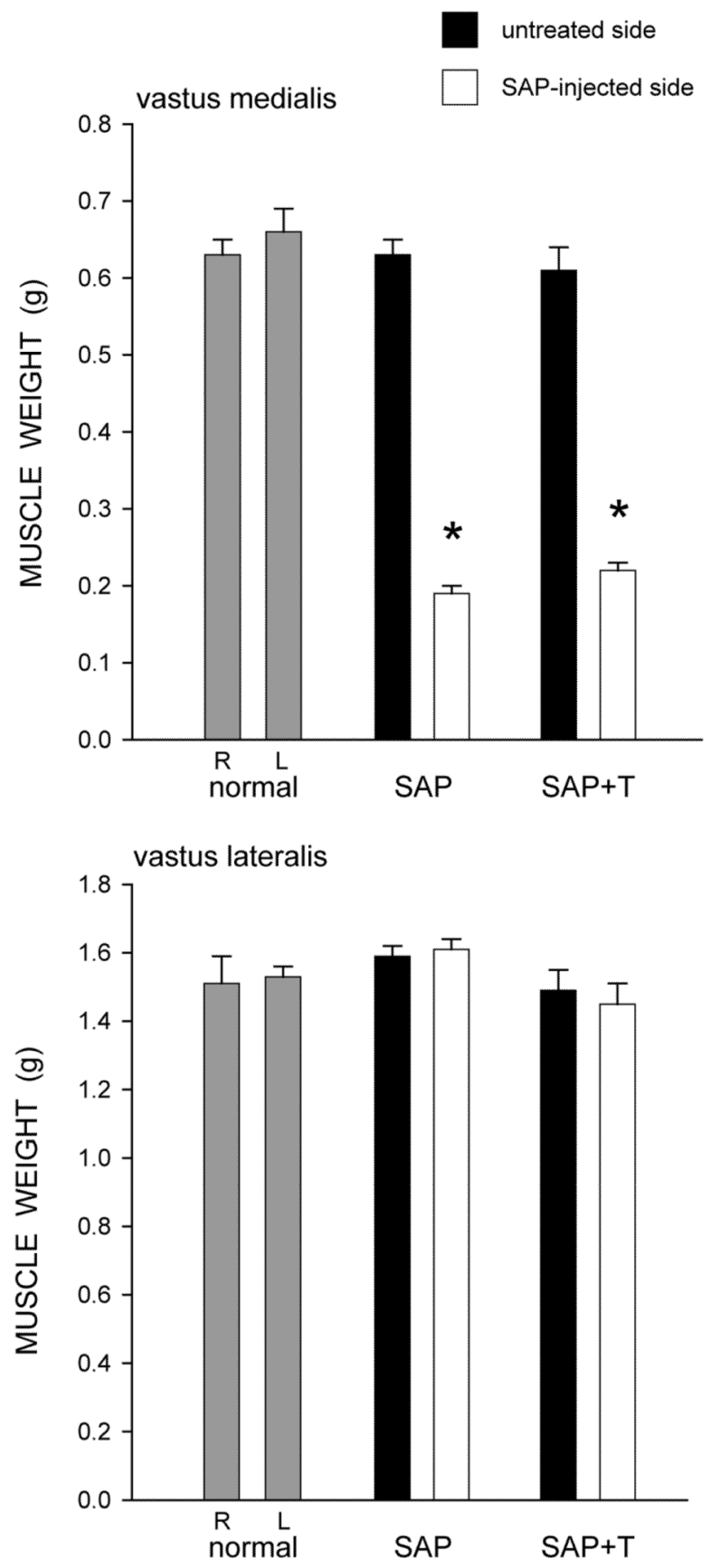

Figure 1.

Weights of the vastus medialis (top) and vastus lateralis (bottom) muscles in normal males and saporin-injected animals that were either untreated (SAP), or treated with testosterone $(\mathrm{SAP}+\mathrm{T})$. Gray bars represent weights from the right $(\mathrm{R})$ and left $(\mathrm{L})$ sides in normal males, filled bars represent weights from the untreated contralateral (right) side of the quadriceps muscle, and unfilled bars represent weights from the saporin injected (left) side of the quadriceps muscle. Saporin injection reduced the weight of the vastus medialis muscle but had no effect on the adjacent vastus lateralis muscle. Testosterone treatment had no effect on muscle weight. Bar heights represent means \pm SEM. * indicates significantly different from normal males. 


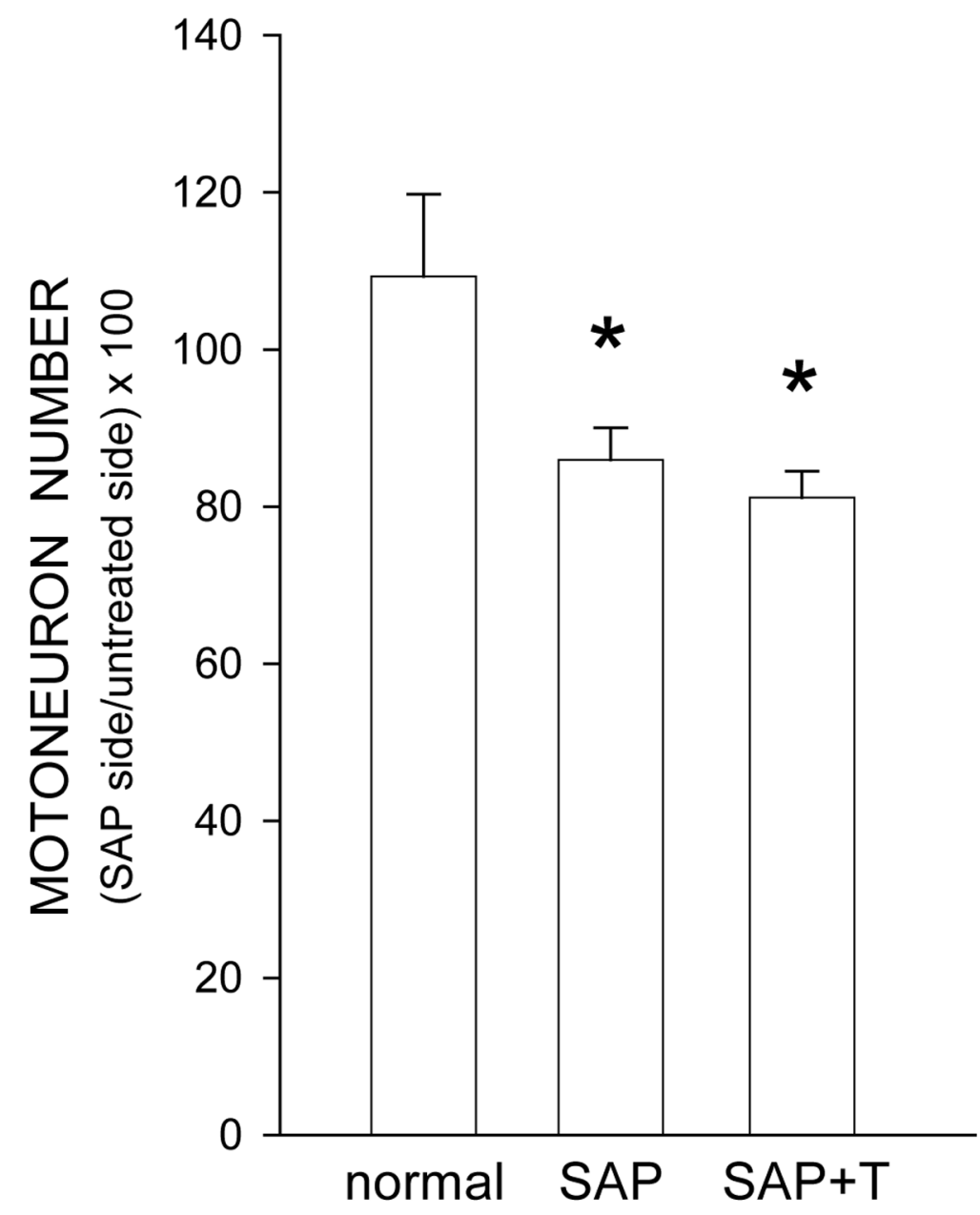

Figure 2.

Numbers of thionin-stained quadriceps motoneurons in normal males and saporin-injected animals that were either untreated (SAP), or treated with testosterone (SAP+T), expressed as a ratio of motoneuron number ipsilateral to the saporin-injected muscle relative to that on the untreated side. Saporin killed approximately $24 \%$ of the ipsilateral quadriceps motoneurons, regardless of hormone treatment. Bar heights represent means \pm SEM. * indicates significantly different from normal males. 

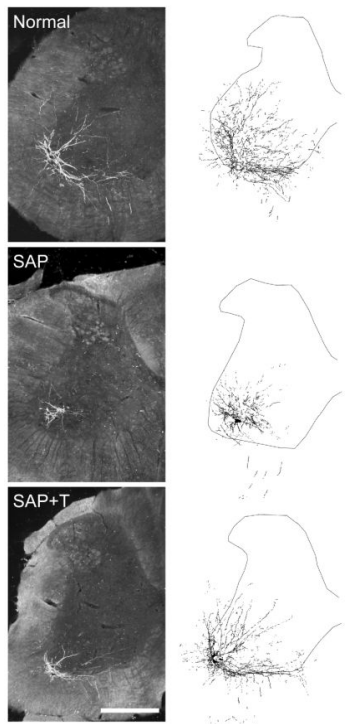

Figure 3.

(Left) Darkfield digital micrographs of transverse hemisections through the lumbar spinal cords of a normal male (top), a saporin-injected male (SAP, middle), and a testosteronetreated saporin male (SAP+T, bottom), after BHRP injection into the left vastus lateralis muscle. (Right) Computer-generated composites of BHRP-labeled somata and processes drawn at $480 \mu \mathrm{m}$ intervals through the entire rostrocaudal extent of the quadriceps motor pool; these composites were selected because they are representative of their respective group average dendritic lengths. Scale bar $=500 \mu \mathrm{m}$. 

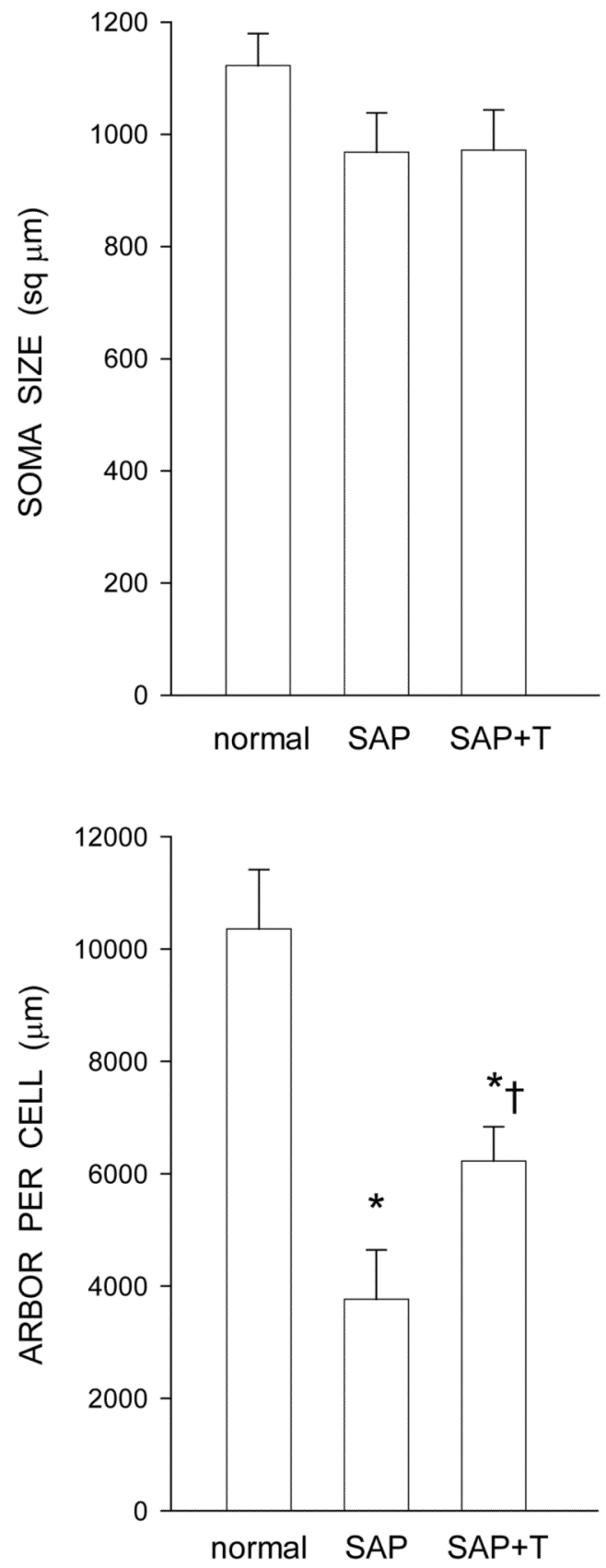

Figure 4.

(Top) Cross-sectional soma areas of quadriceps motoneurons in normal males and saporininjected animals that were either untreated (SAP), or treated with testosterone (SAP+T). Following saporin-induced motoneuron death, the average soma areas of surviving nearby motoneurons decreased by approximately $14 \%$, regardless of hormone treatment, but these reductions were not statistically significant. (Bottom) Dendritic lengths of quadriceps motoneurons of normal males and saporin-injected animals that were either untreated (SAP), or treated with testosterone (SAP+T). Following saporin-induced motoneuron death, surviving nearby motoneurons lost almost $64 \%$ of their dendritic length. Treatment with testosterone attenuated this dendritic atrophy. Bar heights represent means \pm SEM. * 
indicates significantly different from normal males. $\dagger$ indicates significantly different from untreated saporin-injected animals. 


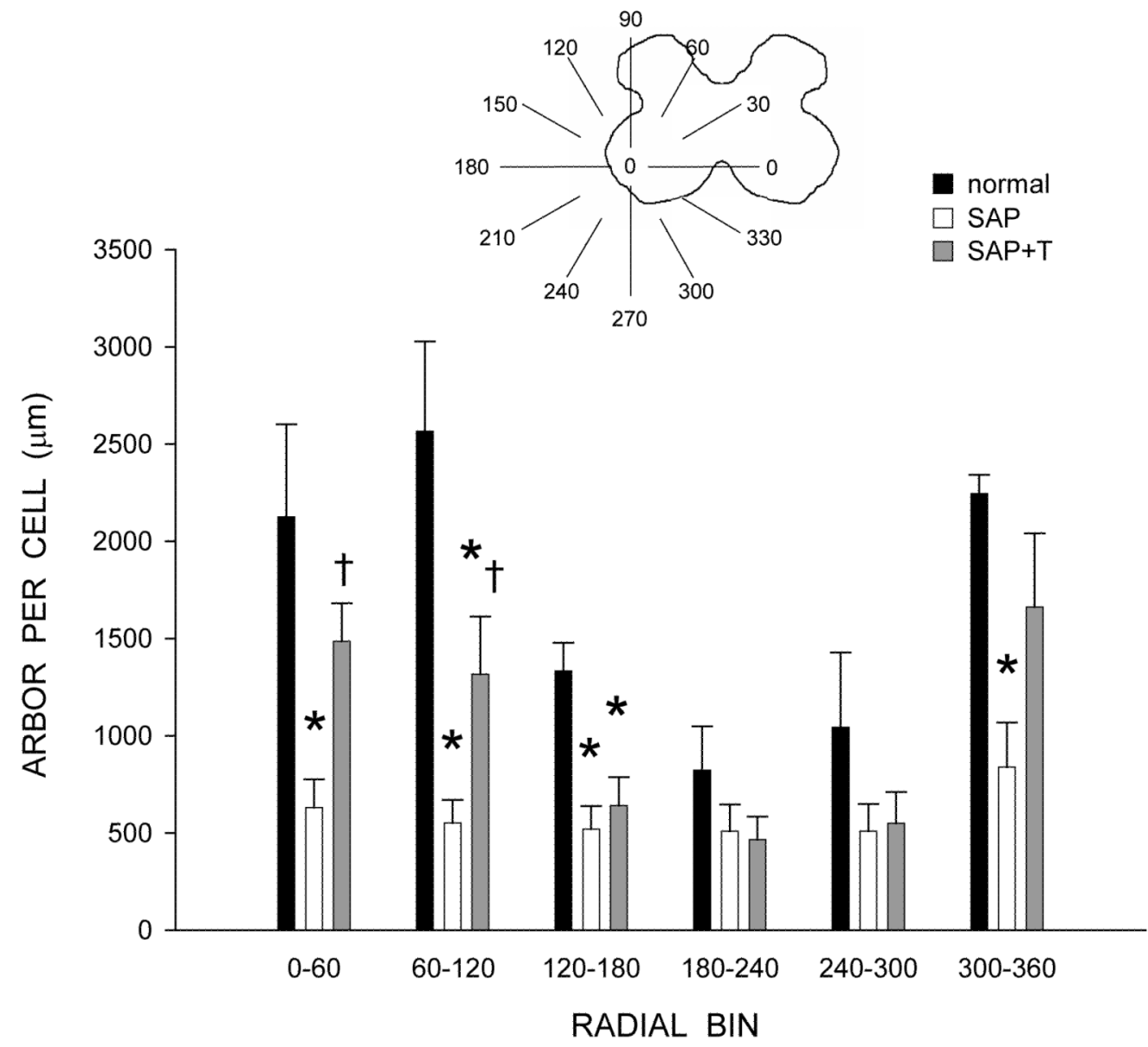

Figure 5.

Inset: Drawing of spinal gray matter divided into radial sectors for measure of quadriceps motoneuron dendritic distribution. Length per radial bin of quadriceps dendrites of normal males (black bars) and saporin-injected animals that were either untreated (SAP, unfilled bars), or treated with testosterone (SAP+T, gray bars). For graphic purposes, dendritic length measures have been collapsed into 6 bins of $60^{\circ}$ each. Quadriceps motoneuron dendritic arbors display a non-uniform distribution, with the majority of the arbor located between $300^{\circ}$ and $120^{\circ}$. Following saporin-induced motoneuron death, surviving nearby motoneurons had reduced dendritic length in every radial bin. Treatment with testosterone attenuated this reduction. Bar heights represent means \pm SEM. * indicates significantly different from normal males. $\dagger$ indicates significantly different from untreated saporininjected animals. 


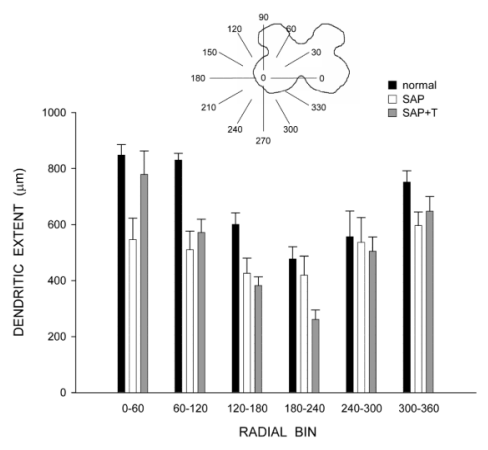

Figure 6.

Inset: Drawing of spinal gray matter divided into radial sectors for measure of quadriceps motoneuron radial dendritic extent. Radial extents of quadriceps dendrites of normal males (black bars) and saporin-injected animals that were either untreated (SAP, unfilled bars), or treated with testosterone (SAP+T, gray bars). For graphic purposes, dendritic extent measures have been collapsed into 6 bins of $60^{\circ}$ each. Following saporin-induced motoneuron death, extent measures of surviving nearby motoneurons in SAP and SAP+T animals did not differ from those of normal animals. Bar heights represent means \pm SEM. 

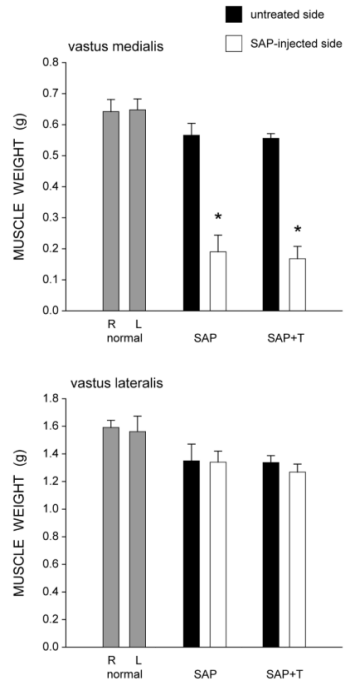

Figure 7.

Weights of the vastus medialis (top) and vastus lateralis (bottom) muscles in normal males and saporin-injected animals that were either untreated (SAP), or treated with testosterone $(\mathrm{SAP}+\mathrm{T})$ used for peripheral nerve recording. Gray bars represent weights from the right $(\mathrm{R})$ and left $(\mathrm{L})$ sides in normal males, filled bars represent weights from the untreated contralateral (right) side of the quadriceps muscle, and unfilled bars represent weights from the saporin injected (left) side of the quadriceps muscle. Saporin injection reduced the weight of the vastus medialis muscle but had no effect on the adjacent vastus lateralis muscle. Testosterone treatment had no effect on muscle weight. Bar heights represent means \pm SEM. * indicates significantly different from normal males. 


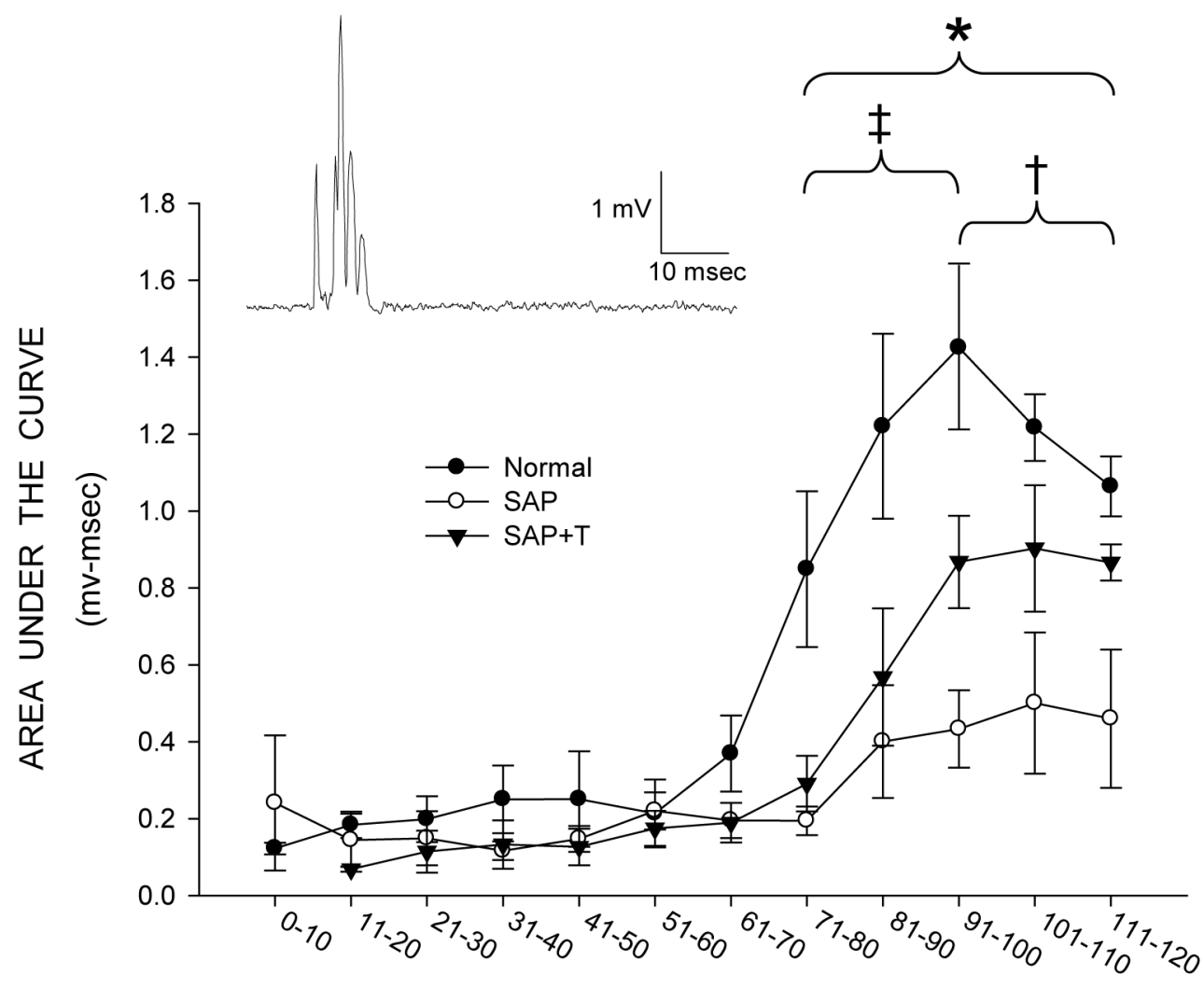

STIMULUS INTENSITY

Figure 8.

Inset: Representative rectified trace from a normal male of quadriceps motor nerve activity following stimulation of the L2 dorsal root. Response amplitudes as a function of stimulus intensity for normal males (filled circles), and saporin-injected animals that were either untreated (SAP, open circles), or treated with testosterone (SAP+T, triangles), measured as area under the curve. Motor nerve activation was significantly reduced in saporin-injected animals, but deficits in response amplitude were attenuated with testosterone treatment. Points represent means \pm SEM. * indicates significant differences between saporin-injected animals and normal males. $\ddagger$ indicates significant differences between saporin-injected animals that were treated with testosterone and normal males. $\dagger$ indicates significant differences between saporin-injected animals that were untreated and those treated with testosterone. 
Table 1

Effects of partial motoneuron depletion on peripheral nerve activation (Means \pm SEM) in normal males and saporin-injected males given no further treatment (SAP) or given supplemental testosterone (SAP+T).

\begin{tabular}{|c|c|c|c|}
\hline & Normal & SAP & SAP+T \\
\hline Background activity (mv) & $\begin{array}{c}0.003 \\
\pm 0.001\end{array}$ & $\begin{array}{c}0.003 \\
\pm 0.0004\end{array}$ & $\begin{array}{c}0.002 \\
\pm 0.00004\end{array}$ \\
\hline Response latency (msec) & $\begin{array}{c}4.22 \\
\pm 0.59\end{array}$ & $\begin{array}{c}4.95 \\
\pm 0.80\end{array}$ & $\begin{array}{c}5.90 \\
\pm 1.61\end{array}$ \\
\hline Maximum peak-to-peak amplitude (mv) & $\begin{array}{c}4.48 \\
\pm 1.05\end{array}$ & $\begin{array}{c}1.32^{*} \\
\pm 0.49\end{array}$ & $\begin{array}{c}3.01 \\
\pm 0.98\end{array}$ \\
\hline Maximum area under the curve (mv-msec) & $\begin{array}{c}2.12 \\
\pm 0.30\end{array}$ & $\begin{array}{c}0.79^{*} \\
\pm 0.26\end{array}$ & $\begin{array}{c}2.15^{\dagger} \\
\pm 0.50\end{array}$ \\
\hline Activity duration (msec) & $\begin{array}{c}3.12 \\
\pm 0.86\end{array}$ & $\begin{array}{c}6.84^{*} \\
\pm 0.71\end{array}$ & $\begin{array}{c}4.43^{\dagger} \\
\pm 0.72\end{array}$ \\
\hline Total spikes & $\begin{array}{c}1.97 \\
\pm 0.54\end{array}$ & $\begin{array}{c}5.74^{*} \\
\pm 0.89\end{array}$ & $\begin{array}{c}4.59^{*} \\
\pm 0.99\end{array}$ \\
\hline
\end{tabular}

* denotes significantly different from normal males

${ }^{\dagger}$ denotes significantly different from SAP males 